Estudios Constitucionales, Año 8, No 2, 2010, pp. 587 - 600.

ISSN 0718-0195

Centro de Estudios Constitucionales de Chile Universidad de Talca

"La cuestión prejudicial y otras garantías de los derechos, en la reforma de la Constitución francesa, según la ley constitucional de 23 de julio de 2008 "

Marc Carrillo

\title{
LA CUESTIÓN PREJUDICIAL Y OTRAS GARANTÍAS DE LOS DERECHOS, EN LA REFORMA DE LA CONSTITUCIÓN FRANCESA, SEGÚN LA LEY CONSTITUCIONAL DE 23 DE JULIO DE $2008^{1}$
}

Marc Carrillo Catedrático de Derecho Constitucional Universidad Pompeu Fabra (Barcelona) mcarrillo@cge.cat>

RESUMEN: La reforma constitucional de 2008 ha tenido una moderada incidencia en el sistema de derechos y libertades. Por un lado ha ratificado derechos ya reconocidos con una formulación constitucional de cierta densidad normativa y ha incorporado nuevos derechos cuyo contenido depende de lo que determine una futura ley orgánica. Pero el avance más relevante se ha producido con la incorporación de la cuestión de inconstitucionalidad, del control incidental a posteriori de las leyes vigentes que atenten contra los derechos y libertades. De esta forma, la Constitución refuerza su jerarquía sobre la ley y la jurisdicción constitucional francesa se acerca al modelo continental europeo.

ABSTRACT: The constitutional reform of 2008 has had a moderate incidence in the system of rights and freedoms. On the one hand has ratified rights already recognized with a constitutional formulation of a certain normative density and it has incorporated new rights the contents of which depend on the future organic law. However, the most important advance has been produced with the incorporation of the question of unconstitutionality, of the incidental control a posteriori of the valid laws that attempt against the rights and freedoms. This way the Constitution reinforces its hierarchy about the law the French constitutional jurisdiction itapproaches to the European continental model.

Palabras Clave: Constitución y poderes públicos. Reserva de ley. Libertades públicas. Derechos fundamentales. Garantías jurisdiccionales. Cuestión de inconstitucionalidad. Ombudsman.

KEY WORDS: Constitution and public powers. Reserve of law. Public Freedom. Fundamental rights. Jurisdictional guarantees. Constitutional question. Ombudsman.

\footnotetext{
${ }^{1}$ Este artículo forma parte de un trabajo más extenso sobre los derechos y libertades en la Constitución francesa, que ha sido publicado también en la revista Cuadernos de Derecho Público, No 34-35 (mayo-diciembre 2008). Instituto Nacional de Administración Pública. Madrid. Enviado por su autor para su publicación en Estudios Constitucionales, el 14 de septiembre de 2010.
} 


\section{LA CUESTIÓN DE INCONSTITUCIONALIDAD DEL ART. 61.1:} UNA VÍA INDIRECTA DE GARANTÍA JURISDICCIONAL

\subsection{La garantía de los derechos por la jurisdicción ordinaria}

Hasta la reforma de $2008^{2}$, la garantía de los derechos y libertades en el ordenamiento jurídico francés ha sido dispensada por la jurisdicción ordinaria. Con la introducción del control a posteriori de la ley cuyo contenido pueda resultar eventualmente atentatorio de los derechos y libertades reconocidos en la Constitución, al justiciable se le abre una vía indirecta de de control abstracto de la ley para la protección de los derechos a través de una verdadera jurisdicción constitucional.

Las causas de la reforma son diversas: las frustradas reformas de la jurisdicción constitucional intentadas en la década de los años noventa; la constante marginación de la Constitución en la garantía de los derechos y libertades a favor del control ejercido por la jurisdicción ordinaria a través del parámetro que ha ofrecido el CEDH de 1950 y la jurisprudencia del TEDH (el llamado control de convencionalidad); y también, por la imposibilidad de los ciudadanos de impugnar una ley inconstitucional (a causa de la jurisprudencia de la "ley pantalla" ya citada) que ha blindado la disposición legislativa de cualquier control de constitucionalidad (Fatin-Rouge Stefanini, 2009, pp. 280-282).

Los términos de la reforma han cristalizado en la adición del artículo 61.1: "Cuando con motivo de una instancia pendiente ante una jurisdicción, se alegue que una disposición legislativa perjudica a los derechos y libertades que garantiza la Constitución, se podrá someter el asunto, tras su remisión por parte del Consejo de Estado o del Tribunal de Casación, al Consejo Constitucional que se pronunciará en un plazo determinado. Una ley orgánica determinará las condiciones de aplicación del presente artículo". Se adopta, pues, el procedimiento constitucional de la cuestión de inconstitucionalidad creada bajo la matriz del reenvío prejudicial europeo del artículo 234 TCE:

A la tercera, por tanto, ha sido la vencida. Pues antes de la reforma de 2008 ya habían habido dos intentos en 1989-90 y en 1993 de introducir la cuestión bajo la denominación, entonces, de excepción de inconstitucionalidad. Pero no hay que olvidar que el Consejo Constitucional en su Decisión No 99-410 DC de 15 de marzo de 1999 (Ley orgánica relativa a Nueva Caledonia, Ley No 85-98 de 25 de enero de 1985) ya declaró no conformes con la Constitución determinadas disposiciones de una ley ya promulgada.

\footnotetext{
${ }^{2}$ La reforma de la Constitución de la V República francesa de 1958, se ha producido por la Ley Constitucional 2008-724, de 23 de julio.
} 
La incorporación del control a posteriori de la ley en Francia supone un paso más en favor de la homologación de la jurisdicción constitucional francesa conforme al modelo continental europeo y un evidente reforzamiento del carácter normativo de la Constitución. Especialmente, en una cuestión tan sensible para el sistema democrático como son los derechos y libertades. Ciertamente, la Decisión del Consejo Constitucional de 16 de julio de 1971, por la que los derechos reconocidos en el Preámbulo forman parte del bloque de constitucionalidad, fue un modesto paso adelante en este sentido pero faltaba la garantía de un órgano constitucional superior con capacidad para declarar nula una ley, cosa que el juez francés no podía hacer. Lo cual -como se ha visto más anteriormente- producía la paradoja de impedir el control de constitucionalidad mientras que el justiciable podía encontrar satisfacción a sus pretensiones en materia de derechos y libertades, a través del control de convencionalidad aplicando al caso la jurisprudencia de Estrasburgo. Así, mientras que el Consejo Constitucional permanecía en gran medida al margen de la protección de los derechos (sólo podía actuar a través del control previo sobre la ley), los jueces y tribunales han sido a través de esta vía -de hecho- la única sede de garantía jurisdiccional de los derechos y libertades. Con la reforma, la situación puede cambiar.

Como ha puesto de relieve el profesor Fromont (2008, pp. 550 y ss.) la jurisdicciones competentes en Francia en derecho privado, penal y administrativo se han caracterizado por su rechazo a controlar por la vía incidental la conformidad con la Constitución de una disposición legislativa y así impedir la aplicación de una ley opuesta a la Constitución. La jurisprudencia de la loi écran (ley pantalla), antes evocada, ilustra bien esta circunstancia. Pero ello no ha sido obstáculo para que, por supuesto, la jurisdicción ordinaria haya desarrollado una jurisprudencia sobre los derechos y libertades garantizados en el preámbulo de la Constitución de 1958 (RENOux, 2008, p. 302). El análisis de esta jurisprudencia permite describir tres situaciones con las que estas jurisdicciones se encuentran a la hora de afrontar la aplicación al caso concreto la relación entre la Constitución y la ley.

Una primera es la que se produce cuando el precepto constitucional es el único a aplicar puesto que no ha sido desarrollado por una ley, o de haberlo sido, la ley no lo contradice. En este caso, lógicamente el juez no tiene dificultad alguna en aplicar la Constitución, que es lo que ha ocurrido en Francia con el derecho de huelga. La segunda es aquella en la que la disposición constitucional y la legislativa no se contradicen, sino que se complementan. Los ejemplos más ilustrativos al respecto se han producido en el ámbito de las relaciones de trabajo y en la función pública. Por tanto, el juez tampoco tiene que afrontar dificultad alguna al respecto; aunque, en los casos excepcionales en los que no exista un precepto legal explícitamente 
aplicable al caso, deberá aplicar directamente la regla constitucional que reconoce el derecho o libertad. La tercera es la más habitual y es la que se produce cuando entre la Constitución y la ley aplicable al litigio no existe una contradicción total que las haga incompatibles, pero la ley sólo será aplicable al caso en la medida que pueda ser interpretada conforme a la Constitución (sous réserve d'intérpretation), y a menudo ello significa que la decisión judicial irá acompañada de una especie de directiva de aplicación de carácter interpretativo. Ahora bien, estos tres supuestos no pueden esconder el que resulta especialmente lacerante: el caso de la ley pantalla, esto es, aquella ley que siendo contraria a la Constitución el juez, no obstante, la aplica al caso concreto porque nunca ha sido declarada inconstitucional y, hasta ahora, tampoco podía cuestionarla ante el Consejo Constitucional.

De todo ello cabe concluir que los derechos y libertades en Francia han formado parte de manera preeminente de la actividad jurisdiccional, pero en un grado inferior que en la República Federal de Alemania o en España. Acorde con lo expuesto, las causas parecen evidentes y que a juicio de Fromont (2008, p. 552) se resumen en: la ausencia de recursos individuales por violación de los derechos ante el Consejo Constitucional; los efectos de la jurisprudencia de la "ley pantalla" y el número reducido de los derechos que operan en las relaciones interprivatos. De ahí que la reforma de 2008 que ha permitido introducir a través de la cuestión de inconstitucionalidad el control a posteriori de la ley, pueda significar un punto de inflexión en este terreno.

\subsection{El control abstracto de la ley aplicable al caso en la jurisdicción ordinaria}

A) El objeto de control. La cuestión de inconstitucionalidad no está prevista para cualquier control abstracto de cualquier ley, sino que está concebida específicamente para aquellas disposiciones legislativas -dice el art. 61-1- que puedan resultar lesivas sobre los derechos y libertades reconocidos por la Constitución. Por tanto, se trata de una cuestión de inconstitucionalidad de objeto limitado, como limitada es la aproximación que la reforma provoca al modelo europeo de justicia constitucional.

Pero, objetivamente, es una garantía jurisdiccional de los derechos frente a los excesos del legislador. Unos excesos que pueden producirse materialmente por infracción del precepto constitucional que reconoce un derecho o libertad específico; pero también formalmente, cuando la reserva de ley del art. 34 de la Constitución, que obliga a que la ley fije las reglas que conciernen a los derechos y libertades, no sea respetada por el Parlamento y habilite al Gobierno para regular una materia que no es de su competencia. A este respecto, la tarea de delimitación funcional 
entre estos poderes del Estado que sin duda le aguarda al Consejo Constitucional será de decisiva importancia. Puesto que en el sistema normativo establecido por la Constitución (art. 34) la regulación general de un derecho o libertad resulta esencial para determinar su contenido, y ello es patrimonio de la ley. Por ello, el control por razones formales no puede ni debe quedar excluido de la función jurisdiccional del Consejo Constitucional como, por el contrario, así lo sostiene algún sector de la doctrina francesa (FATIN-Rouge StÉFAnini, 2009, p. 282).

En otro orden de temas relevantes sobre el objeto de control, cabe subrayar que además de las leyes promulgadas con posterioridad a la Constitución, el constituyente de 2008 no ha querido cerrar las puertas al control de constitucionalidad también de las leyes anteriores a 1958. Al referirse el art. 61-1 a una disposición legislativa cuyo contenido resulte atentatorio a los derechos y libertades, no está excluyendo temporalmente a ninguna ley. No hay obstáculo constitucional a que las leyes viejas y las leyes nuevas respecto al momento constituyente que dio lugar a la V República sean objeto de la cuestión de inconstitucionalidad. Lo que, por otra parte, resulta coherente con el origen histórico del parámetro de constitucionalidad en materia de derechos y libertades que de acuerdo con la jurisprudencia constitucional sentada desde la Decisión de 1971, data del momento revolucionario de 1789.

Otra cuestión relevante que concierne al objeto del control es la relativa a los valores y principios constitucionales. No se trata de derechos y libertades, pero es obvio que los derechos quedan vinculados al contenido material de aquéllos. Resultan inseparables unos de otros. Así, por ejemplo, cuando el art. 34 se refiere a que la ley debe fijar las reglas concernientes a la libertad, el pluralismo y la independencia de los medios de comunicación, es evidente que el control de constitucionalidad sobre una ley que se refiera a algunos de los múltiples aspectos del derecho a la información o de la libertad de expresión, deberá tener en cuenta si dichos valores son respetados por el legislador ordinario. La razón de ello no es otra que el valor normativo que atesoran tanto los valores como los principios constitucionales, como elementos que coadyuvan a la interpretación de las disposiciones legislativas. En este contexto, además de la decisiva aportación que pueda hacer el Consejo Constitucional para establecer unas reglas coherentes y armonizadas de interpretación, el papel a jugar por los jueces y tribunales deberá ser también de una gran importancia (VerpaUX, 2008, p. 1883).

B) La legitimación para plantear la cuestión de inconstitucionalidad. No es universal para todos los jueces y tribunales de la jurisdicción ordinaria, como en el caso español, sino restringida sólo para dos altos órganos jurisdiccionales. En efecto, el art. 61-1 establece que el incidente procesal de la cuestión de inconsti- 
tucionalidad puede ser planteado únicamente por el Consejo de Estado o la Corte de Casación. Las dos instancias paradigmáticas de la jurisdicción administrativa y de la llamada jurisdicción judicial en Francia, que forman parte de la historia de su Derecho Público. De esta forma, la reforma de 2008 se aleja del modelo que representan, por ejemplo, Alemania, Italia y España, para el acceso por esta vía procesal a los tribunales constitucionales, asimilándose mucho más al de Austria, donde la cuestión es promovida sólo por los tribunales de apelación y, eventualmente, también por el Tribunal Constitucional a través de la autocuestión.

La incorporación en el sistema constitucional francés de la cuestión de inconstitucionalidad (BON, 2009, p. 77) o también prejudicial (VerPAuX, 2008, p. 1884), según las diversas expresiones empleadas por la doctrina francesa, ha sido vista con moderada esperanza, como un camino para asegurar la jerarquía normativa de la Constitución (Drago, 2008, p. 324). Sin bien se constata una cierta coincidencia en que el filtro que pueden llegar a realizar el Consejo de Estado y la Corte de Casación como únicos órganos jurisdiccionales legitimados para plantearla, puede resultar un freno excesivo para la finalidad perseguida, esto es, que se extiendan las posibilidades del control incidental y a posteriori de la leyes en vigor. Y que, asimismo, la cuestión sea una vía a la que el justiciable pueda indirectamente acogerse para la garantía de sus derechos ante las infracciones constitucionales cometidas por el legislador ordinario.

Seguramente, habrá que esperar a la definición del régimen jurídico que establezca la ley orgánica del Consejo Constitucional. Por ejemplo, los criterios de admisión, acerca del juicio de relevancia y de validez que justifiquen su planteamiento ante la jurisdicción constitucional. En este sentido, cabrá determinar si la función del Consejo de Estado y de la Corte de Casación es la de ser meros receptores de recursos, una especie de buzón de correos de las cuestiones de inconstitucionalidad; o bien, si la función ha de ser de control acerca de la adecuación de su planteamiento (PHILIPPE, 2008, p. 213). Es evidente que la primera sería un absurdo total y es la segunda la que ha de forzosamente prosperar, como una forma que incentive un diálogo jurídico controlado entre las dos jurisdicciones.

Pero sentado ello, la ley orgánica deberá determinar el régimen de relación entre los dos órganos jurisdiccionales legitimados para promoverla y el resto de los jueces civiles, administrativos y penales que la han de impulsar, que son quienes conocen bien la causa en la que se aplica la ley presuntamente viciada de inconstitucionalidad. Y no sólo eso, sino también será preciso determinar la posición procesal que deben adoptar las partes (las personas físicas o jurídicas) en el proceso ad quo, en relación con el proceso ad quem ante el Consejo Constitucional. Porque 
no hay que olvidar que la cuestión de inconstitucionalidad está concebida como una vía de garantía de los derechos y libertades.

Otra cuestión especialmente importante serán los plazos que establezca la ley orgánica para plantear la cuestión y para resolverla por el Consejo Constitucional. Existe una lógica y comprensible coincidencia en la doctrina francesa en el sentido de que sean cortos. Los ejemplos en sentido contrario y sus efectos devastadores sobre la utilidad de la cuestión como garantía de derechos y libertades (por ej., en España) son un buen punto de referencia de carácter disuasorio. Otro argumento en el mismo sentido, es que de no ser así, el control de convencionalidad al que ya se ha hecho referencia anteriormente y que habitualmente aplica la jurisdicción ordinaria francesa, tendría de entrada ganada la partida frente al control de constitucionalidad (BON 2009, p. 79; PHILIPPE, p. 215; GaïA, 2008, p. 201). Porque de lo que se trata es de reforzar la jurisdicción constitucional como unificadora de la jurisprudencia, de acuerdo con un criterio basado en la interpretación armónica de la Constitución y del CEDH, vinculado a la jurisprudencia de Estrasburgo. Para lo cual, y en otro orden de temas de relevancia, la ley orgánica deberá atender también a las necesidades en orden a la dotación de personal y apoyo material que el ejercicio de esta nueva competencia ha de comportar para el Consejo Constitucional.

C) ¿Es posible la autocuestión del Consejo Constitucional en materia de derecho electoral? El Consejo Constitucional es juez en primera y única instancia de la validez de las elecciones a la Presidencia de la República, de las elecciones a diputados y senadores y de los referéndums previstos en los artículos 11 y 89. En todos estos supuestos, el contenido de la legislación electoral supone, entre aspectos la regulación del derecho fundamental de sufragio, un derecho de participación política. En consecuencia, una vez instaurada la cuestión de inconstitucionalidad por el artículo 61-1 en los términos ya descritos, nada habría de impedir para que al igual que, por ejemplo, en los casos español y austriaco, el Consejo Constitucional pueda llegar a plantearse la constitucionalidad de una ley electoral que está impelido aplicar en las convocatorias electorales citadas.

D) Los efectos de las decisiones del Consejo Constitucional en los supuestos de cuestiones de inconstitucionalidad. El artículo 62 de la Constitución ha sido modificado para prever los efectos de una decisión de control a posteriori de la ley vigente. Dice así: "Una disposición declarada inconstitucional en base al artículo 61-1 será derogada a partir de la publicación de la decisión del Tribunal Constitucional o de una fecha posterior fijada en dicha decisión. El Consejo Constitucional determinará las condiciones y los limites en que los efectos producidos por la disposición puedan ser susceptibles de ser cuestionados". 
Por tanto, los efectos de la decisión del Consejo son, en principio, la derogación de la ley declarada contraria a la Constitución con carácter erga omnes, motivo por el cual es palpable el reforzamiento de la jerarquía normativa de la Constitución frente a la ley y, a su vez, el carácter más propio de jurisdicción constitucional que adopta el Consejo Constitucional. El alcance de dichos efectos es ex nunx, pero en principio el art. 62 atribuye margen de maniobra a la decisión del Consejo para modular los efectos y, en este sentido, no parece que excluya la posibilidad de los efectos ex tunc. Por ejemplo, tratándose de leyes sobre derechos y libertades parece razonable que el Consejo pueda admitir esta consecuencia cuando del resultado de su decisión se derive una situación más favorable para el justiciable en materia penal o sancionadora. Ello, sin perjuicio de reconocer que como criterio general, lo lógico es que el Consejo Constitucional evite la variación o transformación de situaciones de derecho ya adquiridas (VERPAUX, 2008, p. 1886).

\section{LAS garantías NO JURISDiCCIONALES: LA RESERVA DE LEY y EL DEFENSOR DE LOS DERECHOS COMO NUEVA AUTORIDAD ADMINISTRATIVA}

\subsection{La reserva de ley y otras garantías}

Las garantías no jurisdiccionales son garantías de relieve jurídico o institucional que, en un plano distinto del derecho de acceso al juez, establecen una serie de condiciones generales para la salvaguarda de los derechos y libertades, que son habituales en un Estado de derecho. Atendiendo al contenido de la reforma constitucional de 2008, procede retener la atención sobre la incidencia que el principio general de reserva de ley puede tener sobre los derechos y las garantías jurisdiccionales previstas por la Constitución francesa.

A) La reserva de ley como garantía general.

El art. 34 determina que ha de ser la ley la que fije las reglas que conciernen a: "los derechos cívicos y las garantías fundamentales atribuidas a los ciudadanos para el ejercicio de las libertades públicas...”. En consecuencia, el ámbito material reservado a la ley es una garantía formal de que la regulación del régimen general de los derechos y libertades corresponde al Parlamento y no al Gobierno. El Parlamento es la representación del pluralismo representativo de la soberanía popular, mientras que el Gobierno lo es sólo de una parte -aunque la más decisiva- de ese pluralismo, que goza de mayoría parlamentaria suficiente para gobernar.

Cuando la Constitución fija que ha de ser la ley la que regule los derechos cívicos, las garantías fundamentales para el ejercicio de las libertades públicas, está fijando un criterio normativo que pretende atribuir a los derechos y libertades, en tanto que pilar fundamental del sistema democrático, la máxima cobertura jurí- 
dica. Y ésta ha de proceder de la ley porque es el resultado del debate más plural que ofrece la representación política que ostenta el Parlamento. Por esta razón la regulación por ley formal aporta una mayor garantía general a los derechos y libertades que la que proporciona el reglamento administrativo del Gobierno. Esta garantía general que establece la Constitución se puede sintetizar en el hecho de que es la ley la que protege al derecho fundamental, mientras que el decreto la oprime (Verpaux, 2008, p. 1884). Más allá de la simplicidad de la frase, en ella se esconde el fondo del problema: la delimitación de los ámbitos materiales entre ley y reglamento.

El constituyente de la Constitución de 1958 limitó el ámbito reservado a la ley, en clara oposición a la tradición monista francesa sobre la posición hegemónica de la ley en el ordenamiento, cuyo ascendente se encuentra en el régimen de la III República y que la IV en gran parte asumió. Así, el artículo 34 definió un ámbito material reservado a la ley; en segundo lugar introdujo una definición dualista, por la que en algunos casos la ley puede "fijar las normas" y fijar detalles relativos a determinadas materias, y en otras materias "determina unos principios fundamentales", de carácter más general, por lo que el margen de acción del reglamento es más amplio; y en tercer lugar, el dualismo normativo, al modo curiosamente germánico, que introduce la Constitución de la V República, determinó que el legislador no puede desbordar el ámbito que le corresponde e invadir el ámbito del poder reglamentario, puesto que como recuerda el art. 37 "tendrán carácter reglamentario todas las materias distintas de las pertenecientes al ámbito de la ley".

El problema que en materia de garantía de los derechos y libertades que ahora se plantea es la adecuada limitación entre los ámbitos que corresponden a la ley y al reglamento. Porque toda deslegalización puede resultar lesiva para la preservación del contenido esencial del derecho. $Y$ es en este terreno, ahora que el Consejo Constitucional podrá ejercer un control a posteriori de la ley promulgada, donde le espera una intensa labor de control formal de la que no podrá eximirse. Porque, como pone de relieve Bon (2009, pp. 61-62), el fracaso de la limitación del ámbito reservado a la ley avalado por la jurisprudencia del Consejo Constitucional no resulta, precisamente, un buen precedente. En efecto, además de lo previsto en el art. 34, esta doctrina extensiva se ha referido también a otros preceptos para definir el ámbito de la ley (art. 66 de la Constitución y los arts. 7 y 8 de la Declaración de 1789); además, el Consejo Constitucional ha optado por difuminar toda diferencia entre las leyes que establecen reglas y aquellas otras que fijan principios generales; y, finalmente, ha admitido que la ley puede intervenir en el ámbito reglamentario. Con lo cual, la inseguridad jurídica que conlleva ha de ser afrontada por el Consejo ante la nueva coyuntura jurídica que nace del 
control de aquella ley que resulte lesiva de derechos y libertades, de tal forma que le habría de hacer reconsiderar la doctrina hasta ahora establecida respecto a la delimitación del ámbito de la ley respecto del ámbito reglamentario.

B) El control de los poderes excepcionales por el Consejo Constitucional. En este ámbito de garantías de carácter general cabe anotar, también, la relevancia de la redacción adicional que se ha incorporado al polémico artículo 16 que regula el Derecho de excepción, que en su primer apartado otorga poderes especiales al Presidente de la República "cuando las instituciones de la República, la integridad de su territorio o el cumplimiento de sus compromisos internacionales estén amenazados de manera grave e inmediata y el funcionamiento regular de los poderes públicos constitucionalmente interrumpido, el Presidente tomará las medidas exigidas por estas circunstancias...".

Como es bien conocido, el carácter genérico de este precepto originario de la Constitución de 1958 y la ausencia de controles explícitos sobre las medidas que podía tomar el Jefe del Estado, además de la evidente incidencia que podían tener sobre los derechos y libertades, permitió valorar en su momento esta previsión constitucional como una puerta abierta a una especie de golpe de Estado permanente, que fue la expresión utilizada en un célebre libro de François Mitterrand (Le coup d'État permanent) ${ }^{3}$, en los años sesenta del siglo pasado, y que después sería Presidente de la República entre 1981 y 1995, sin que dicho precepto experimentase reforma alguna en dicho período.

Pues bien, la reforma ha introducido un importante control que corre a cargo del Consejo Constitucional sobre la aplicación de las medidas excepcionales que inevitablemente han de afectar al ejercicio de los derechos, en la medida en que nada excluye que algunos de ellos puedan ser suspendidos durante el período excepcional. Concretamente, la reforma establece que "Tras los treinta días de ejercicio de los poderes excepcionales, el Consejo Constitucional podrá ser requerido por el Presidente de la Asamblea Nacional, el Presidente del Senado, sesenta diputados o sesenta senadores, a fin de examinar si se siguen cumpliendo las condiciones enunciadas ... en el primer apartado. El Consejo Constitucional se pronunciará lo antes posible mediante anuncio público. Procederá de pleno derecho a este examen y se pronunciará en las mismas condiciones al término de sesenta días de ejercicio de los poderes excepcionales y en cualquier momento pasado dicho plazo".

En el tercer apartado del art. 16 también se establece que durante los primeros treinta días el "Consejo Constitucional será consultado" sobre la adecuación de las medidas tomadas para restaurar el orden alterado, si bien nada se dice sobre los

${ }^{3}$ F. Mitterrand, Le coup d'état permanent. Plon. Paris, 1964, 
efectos de la opinión o decisión que el órgano jurisdiccional tome. De la lógica del precepto se deduce que serán consultivos y no vinculantes. Si bien en estos primeros treinta días de excepción quedan fuera de control, en una especie de limbo constitucional, no deja de ser un progreso el establecimiento de un cierto control posterior a los primeros treinta días, el incorporado por la reforma de 2008, que parece presentar un grado más intenso, dado que la petición para que el Consejo Constitucional emita su parecer es a instancia del Parlamento (Asamblea Nacional y Senado). Pues si bien la Constitución no precisa sus efectos jurídicos, resulta difícil que institucional y, por tanto, políticamente, el Presidente de la República pueda hacer abstracción de un parecer del Consejo Constitucional que sea contrario a las medidas que haya adoptado.

c) Acceso del justiciable al Consejo Superior de la Magistratura. En la extensa reforma del órgano representativo del gobierno de la magistratura, dirigida a asegurar una mayor independencia de lo que la Constitución sigue denominando Autoridad Judicial (que no Poder Judicial), cabe destacar la previsión contemplada en el penúltimo apartado de la nueva redacción del artículo 65: "El Consejo Superior de la Magistratura podrá entender de un asunto presentado por un justiciable en las condiciones fijadas por una ley orgánica".

La indeterminación material de este precepto es notoria. Sin embargo, su previsión constitucional, por genérica que pueda resultar, constituye un paso adelante a fin de asegurar que el Consejo pueda actuar garantizando, en el ámbito de sus competencias administrativas (en especial, en el régimen disciplinario aplicable a los jueces) el derecho del justiciable a la tutela judicial. Esto es, el derecho de acceso a la jurisdicción, de acuerdo con un procedimiento contradictorio que concluya con una resolución fundamentada conforme a Derecho.

\subsection{El Defensor de los Derechos}

La nueva fase de la constitucionalización de los derechos que se deriva de la reforma de 2008 se ha traducido también en la adopción de una nueva autoridad para la defensa de los derechos y libertades (art. 71-1, Título XI bis), denominada el Defensor de los Derechos. La configuración constitucional de esta modalidad francesa de ombudsman responde a las siguientes características:

- Nombramiento, mandato e incompatibilidades. Es nombrado por el Presidente de la República por un mandato de seis años no renovable de acuerdo con un procedimiento previsto en la ley orgánica, la cual deberá establecer que su nombramiento se llevará a cabo previo anuncio público de la comisión permanente de cada Cámara del Parlamento y siempre que la suma de los votos negativos en cada comisión no represente al menos los 3/5 de los votos emitidos en el seno de 
ambas comisiones (art. 13 de la Constitución, un precepto que también ha sido adicionado con la reforma de 2008). Sus funciones son incompatibles con las de miembro del Gobierno y del Parlamento, sin perjuicio de aquellas otras que pueda fijar la ley orgánica.

- El objeto de sus funciones constitucionales es velar por el respeto de los derechos y las libertades, ante todas las administraciones públicas, así como cualquier organismo que desarrolle un servicio público o respecto del cual la ley orgánica le atribuya competencias.

- El acceso al Defensor puede ser a instancia de cualquier persona que se considere perjudicada por el funcionamiento de un organismo o servicio público. Y también puede serlo de oficio.

- Sus competencias y las modalidades de ejercicio serán definidas por la ley orgánica.

- Relación con otras instituciones de la República. El Defensor debe dar cuenta de su actividad ante el Presidente de la República y el Parlamento.

De la configuración de este nuevo órgano constitucional se derivan algunas consecuencias sobre su naturaleza jurídica. Pero habrá que esperar a la futura ley orgánica para disponer de datos más completos para su definitivo encuadramiento institucional y su relación con otras instituciones de defensa de los derechos. Sobre todo porque, si bien es un órgano de nueva creación, su aparición en el panorama institucional francés se añade a toda una pléyade de autoridades administrativas de carácter regulador ya existentes, que fueron concebidas también para aportar una garantía no jurisdiccional sobre los derechos y libertades. Es el caso del Médiateur (Mediador), del Défenseur des enfants (Defensor de la infancia), de la HALDE, l'Haute Autorité de lutte contre les discriminations et por l'égalité (la Alta Autoridad para la lucha contra las discriminaciones y por la igualdad); la CNIL, la Comission National de l'Informatique et des libertés (Comisión Nacional de la Informática y de las libertades); le Contrôleur General des Lieux de privation des libertés (el Controlador General de los centros de privación de libertad) creado por la Ley No 2007-1545 de 30 de octubre de 2007, etc.

En cuanto a la naturaleza de este nuevo órgano, y a reserva de lo que precise la futura ley orgánica, la configuración constitucional del Defensor para decantarse claramente por una institución de defensa de los derechos y libertades entendida como magistratura de persuasión, siguiendo parcialmente en este sentido la estela dejada por la mayoría de los ombudsman existentes en Europa. Sobre todo, en la medida que el art. 71.1 se refiere a sus funciones, definiéndolas como una acción de velar por el respeto a los derechos en el ámbito de las diversas administraciones públicas. Por lo que no parece que vaya a tener poder decisorio, sino más bien 
persuasivo sobre las administraciones y empresas públicas objeto de control no jurisdiccional. Incluso cuando la lesión efectiva no se haya producido, como apuntaba el informe Balladur (PHILIPpe, 2008, p. 217). Especialmente, en los supuestos de mala administración (Plessix, 2008, p. 62), es decir en aquéllos de gestión deficiente $\mathrm{o}$, incluso, de abuso de poder que puedan resultar lesivos para los intereses del ciudadano. Así cabe deducirlo cuando la Constitución se refiere a la queja de cualquier persona que "se considere perjudicada por el funcionamiento de un servicio público o de un organismo..." administrativo sujeto al control del Defensor.

Anteriormente se ha apuntado que el Defensor francés sigue parcialmente el ejemplo de otras instituciones similares europeas creadas al albur de la llamada ombudsmania generada en Europa en las últimas décadas del siglo pasado. Lo que ciertamente obliga a precisar que, a diferencia del caso sueco en el que se han inspirado tantos otros como es el caso del Defensor del Pueblo en España, el Defensor galo no es elegido por el Parlamento, sino que es nombrado por el Presidente de la República ante el que, además, ha de rendir cuentas de su actuación, razón por la cual su autonomía orgánica y funcional será, objetivamente, menor de la que, en principio, disponen otras instituciones similares.

En cuanto al objeto de su actividad, o si se quiere el ámbito de su actuación persuasiva, cabe entender que son todas las administraciones públicas, tanto las de carácter territorial como las de carácter corporativo o institucional. Parece claro, sin embargo, que queda excluida su actuación en las relaciones interprivatos.

Finalmente, cabe subrayar que un reto importante de la futura ley orgánica, será el de precisar las formas de relación y de coordinación de funciones con las otras autoridades de regulación antes citadas, a fin de evitar posibles solapamientos.

\section{BiBLiografía}

Bon, Pierre, "La Constitución de la V Républica cumple cincuenta años". Revista Española de Derecho Constitucional, No 85, Madrid 2009, pp. 45-81.

Drago, Guillaume, "Le Conseil Consitutionnel à la croisée des chemins". Cinquantième anniversaire de la Constitution française. Dalloz. Paris 2008, pp. 315-328.

Fatin-Rouge Stéfanini, Marthe, "Le Conseil Constitutionnel dans la revision constitutionnelle du 23 juillet 2008 sur la modernisation des institutions". Revue Française de Droit Constitutionnel, No 78, Paris, avril 2009, pp. 269-298.

Fromont, Michel, "Les droits fondamentaux dans l'ordre juridique de la République fédérale allemande”, Mélanges Eisenmann. Paris 1975. 
Fromont, Michel, "La découverte des droits fondamentaux, une oeuvre inachavée. En: Cinquantième anniversaire de la Constitution française. Dalloz. Paris 2008, pp. 545-550.

GAÏA, Patrick, "Le contrôle de conventionnalité". Revue Française de Droit Constittutionnel, No extraordinario (Après le Comité Balladur. Réviser la Constitution en 2008?), Paris 2008, pp. 201-207.

Milacic, Slobodan, "De la rédecouverte" des droits fondamentaux sous la Vème République. A chaqué époque ses droits fondamentaux. En: Cinquantième anniversaire de la Constitution française. Dalloz. Paris 2008, pp. 553-561.

Philippe, Xavier, "Les propositions d'améliorations de la protection des droits fondamentaux". Revue Française de Droit Constittutionnel, No extraordinario (Après le Comité Balladur. Réviser la Constitution en 2008?). Paris 2008, pp. 209-222.

Plessix, Benoït, "Des droits nouveaux pour les citoyens", JCP No 31-35, 30/7/2008, Juris-Classeur-Pro (JCP), Paris, pp. 59-63.

Renoux, Thierry, “De l'article 64 de la Constitution et l'independence de l'autorité judiciare à l'article 16 de la Déclaration des Droits et l'independance de la justice”. 1958-2008. En: Cinquantième anniversaire de la Constitution française. Dalloz. Paris 2008, pp. 293-306.

VerPaux, Michel, “Question préjudicielle et renoveau constitutionnelle”. Actualité Jurídique. Droit Administratif (AJDA) de 13/X/2008, Paris, pp. 1879-1886.

WaChSMAnn, Patrick, "Les droits fondamentaux, sans le valoir ni le vouloir". 19582008. En: Cinquantième anniversaire de la Constitution française. Dalloz. Paris 2008, pp. 563-569. 